\title{
Influence of green state processing on the properties of diamond/zinc sulphide composites
}

\author{
L. A. XUE*, R. RAJ \\ Materials Science and Engineering Department, Cornell University, Ithaca, NY 14853, USA
}

Diamond-reinforced zinc sulphide composites have increased toughness as compared to that of pure zinc sulphide. While the mechanical properties of the composites are relatively insensitive to green state processing, the optical properties are greatly affected by the processing which governs the quality of diamond dispersion. Improved dispersion and hence good optical transmission have been achieved by shear mixing and by freeze milling.

\section{Introduction}

Zinc sulphide is an excellent far infrared transmitting material in the $8-12 \mu \mathrm{m}$ band. In general, materials with strong chemical bonds exhibit good thermomechanical properties but poor infrared transmission, and materials showing good far infrared transmission possess weaker chemical bonds and poor mechanical properties [1]. For instance, a simple comparison in Table I made between $\mathrm{ZnS}, \mathrm{ZnSe}$ and CdTe (three commonly used far infrared materials) shows that there is a conflict of interests between optical and mechanical properties in materials for far infrared application. There is an exception in this regards, i.e. diamond. Known for its excellent mechanical properties, diamond is also transparent to electromagnetic radiation up to radio wavelength [2], which makes it an outstanding candidate for infrared transmission materials. Unfortunately, the utilization of bulk diamond is not practically feasible.

The drawbacks of these conventional far infrared materials led to the development of new engineering materials in the form of a composite with good optical as well as mechanical properties [3]. The introduction of second-phase inclusions into ceramics can raise the fracture energy of the material and hence result in a higher fracture toughness $[4,5]$. For small 'compared with the wavelength of the incident light' dielectric spheres embedded in a matrix, if $k r<<1$, then the scattering section, $Q_{\mathrm{s}}$, can be simplified to the following form [6]:

$$
Q_{\mathrm{s}}=(8 / 3) k^{4} r^{4} \operatorname{Re}\left[\left(\varepsilon_{\mathrm{i}}-\varepsilon_{\mathrm{m}}\right) /\left(\varepsilon_{\mathrm{i}}+2 \varepsilon_{\mathrm{m}}\right)\right]^{2}
$$

where $k$ is the wavevector of the light incident on the sphere of radius $r$, and $\varepsilon_{\mathrm{i}}, \varepsilon_{\mathrm{m}}$ the dielectric constant of the inclusion phase and the matrix, respectively. It follows from Equation 1 that minimal scattering can be achieved by matching the refractive indices $n(\varepsilon$ $=n^{2}$ ) of matrix and inclusion and by reducing the inclusion size to a value significantly less than that of the wavelength of the incident radiation.

Diamond is transparent in the far infrared range and has a similar refractive index value to that of $\mathrm{ZnS}$ (see Table I). Therefore it is an ideal candidate for reinforcing $\mathrm{ZnS}$. Such composites with high fracture toughness can be made, but the optical properties depend strongly on the green state processing which determines the quality of diamond particle dispersion in $\mathrm{ZnS}$ matrix. On the other hand, the toughness appears to be relatively insensitive to the processing.

\section{Experimental procedure}

2.1 Material preparation

A high-purity ZnS powder (99.9\%) with particle size in the submicrometre range was employed throughout

TABLE I Optical and mechanical properties of typical far infrared window materials

\begin{tabular}{llllllll}
\hline Material & $\begin{array}{l}\text { Useful range } \\
(\mu \mathrm{m})\end{array}$ & $\begin{array}{l}\text { Young's } \\
\text { modulus } \\
(\mathrm{GPa})\end{array}$ & $\begin{array}{l}\text { Modulus of } \\
\text { rupture } \\
(\mathrm{MPa})\end{array}$ & $\begin{array}{l}\text { Refractive } \\
\text { index } \\
\text { at } 10 \mu \mathrm{m}\end{array}$ & $\begin{array}{l}\text { Thermal expansion } \\
\text { coefficient } \\
\left(10^{-6} \mathrm{~K}^{-1}\right)\end{array}$ & $\begin{array}{l}\text { Melting } \\
\text { temperature } \\
(\mathrm{K})\end{array}$ & $\begin{array}{l}\text { Estimated safe thermal } \\
\text { shock temperature } \\
\text { range }(\mathrm{K})\end{array}$ \\
\hline $\mathrm{ZnS}$ & $0.4-14.5$ & 97 & 97 & 2.199 & 6.7 & 2103 & 150 \\
$\mathrm{ZnSe}$ & $0.45-21.5$ & 69 & 48 & 2.407 & 7.5 & 1793 & 90 \\
$\mathrm{CdTe}$ & $0.9-32$ & 35 & 6.2 & 2.672 & 5.7 & 1364 & 30 \\
Diamond & $>0.23$ & 908 & $\sim 20000$ & 2.376 & 2 & $>3350$ & 11000 \\
\hline
\end{tabular}


the study. Diamond powders of various sources were tried, including Dubbeldee (DB), Dupont (DP), Diamond Unlimited (DU), and General Electric (GE).It was found that DB and DP diamonds were too rich in metallic impurities which caused a lot of absorption. GE diamond was found to be the most satisfactory and thereafter used in the present work. The particle size of as-received GE powder ranged from $0.01-1 \mu \mathrm{m}$.

Various techniques were applied to mix $\mathrm{ZnS}$ with diamond:hand mixing using an agate mortar and pestle; ultrasonic agitation plus magnetic bar stirring; shear mixing using a stomacher blender (Labblender 80, Tekmar); and freeze impact mixing using a freeze miller (6700 Freezer/Mill, Spex). This stage of green state processing proved to be very important because the quality of dispersion of diamond particles in the matrix depends on it.

The diamond- $\mathrm{ZnS}$ powder mixtures were hot-pressed in a bore die made of molybdenum or of TMZ under pressure of $200 \mathrm{MPa}$ and in the temperature range $850-1000^{\circ} \mathrm{C}$ for $30 \mathrm{~min}$. R.f. induction heating was used. Graphite foil was inserted to separate the specimen from the die material. The hot-pressing atmospheres were either reducing (high vacuum; Ar + $4 \% \mathrm{H}_{2} ; \mathrm{He}+4 \% \mathrm{H}_{2}$ ) or inert (Ar). No substantial difference in terms of the specimen quality was found among these atmospheres, although the $\mathrm{He}-\mathrm{H}_{2}$ mixture seemed to give slightly better results.

The final densities of the hot-pressed samples were no less than $99 \%$ theoretical. The as-hot-pressed discs were ground and polished for optical measurement and for mechanical testing. The finished specimens for optical measurement had a diameter of $11 \mathrm{~mm}$ with a thickness of $0.6-1 \mathrm{~mm}$.

\subsection{Infrared transmission measurement}

Transmission of our hot-pressed samples were determined from $20 \mu \mathrm{m}$ to a $2.5 \mu \mathrm{m}$ using a double-beam grating-type spectrophotometer (Perkin-Elmer). In order to reduce our measurement error, two different transmission spectra were measured and compared for each sample. The biggest source of error in our measurement is sample inhomogeneity; some samples, especially samples at earlier stages, showed about $10 \%$ variation of transmission if a small area of sample was used. To obtain an average value over various sample areas, a relatively large size beam (i.e. about $5 \mathrm{~mm}$ diameter was used.

\subsection{Fracture toughness measurement}

The fracture toughness values of pure $\mathrm{ZnS}$ and composites of various diamond contents were determined using a micro-indentation technique $[7,8]$. Vickers diamond pyramid indentations were made on polished specimens with a load range of 4-20 N. The indents and crack dimensions were measured to an accuracy of $\sim 1 \mu \mathrm{m}$ by a moving hairline in the microscope attached to the micro-hardness tester (Tukon, Wilson Instrument). The data were obtained on at least four indents for each load.

\section{Results and discussion}

\subsection{Optical transmission}

Fig.1 shows infrared transmission spectra of pure $\mathrm{ZnS}$ (Curve A), $2 \mathrm{wt} \%$ diamond composite, and $10 \mathrm{wt} \%$ diamond composite (Curve C), for which the diamond and $\mathrm{ZnS}$ powders were hand mixed during green state processing. These specimens were hot-pressed at $900^{\circ} \mathrm{C}$ and at $200 \mathrm{MPa}$ in vacuum. These were asmeasured transmissions which include reflection loss from two air-specimen interfaces (about 26\%). Therefore, the pure $\mathrm{ZnS}$ actually gave an $100 \%$ transmission at $10 \mu \mathrm{m}$ wavelength $\left(1000 \mathrm{~cm}^{-1}\right)$. The composites, however, exhibited poor transparency even at $2 \%$ diamond level, and turned out to be completely black as the diamond content increased to $10 \mathrm{wt} \%$. The curve of $2 \%$ diamond shows a characteristic of scattering loss. The absorption peak at $2350 \mathrm{~cm}^{-1}$ is probably due to $\mathrm{CO}_{2}$ gas trapped in the sample. The poor optical properties of these composites are attributed to the poor dispersion of the diamond particles in the $\mathrm{ZnS}$ matrix in the hand mixing technique which is insufficient to break down agglomerates of diamond and $\mathrm{ZnS}$, and in obtaining a homogeneous distribution of diamond particles in the matrix. This is evident from Fig. 2a which shows a scanning electron micrograph of a polished section of $10 \mathrm{wt} \%$ diamond composite (Sample C in Fig. 1). The pits and holes seen in the picture, some as large as $10 \mu \mathrm{m}$ in dimension, were places from which diamond agglomerates spalled during polishing. These diamond agglomerates of size comparable to the wavelength, acted as multiple scattering centres and blocked the passage of the incident light.

To solve this problem, other mixing techniques were used to break down the agglomerates and to achieve better dispersion of diamond in $\mathrm{ZnS}$. Ultrasonic mixing worked to some extent. Fig. 3 shows the improved results from ultrasonic treatment. Note the less steep slope for the $2 \%$ diamond composite as compared to that in Fig. 1, indicating a reduced contribution from scattering. The shallow absorption peak at $2870 \mathrm{~cm}^{-1}$ was from the $\mathrm{C}-\mathrm{H}$ bond, which can

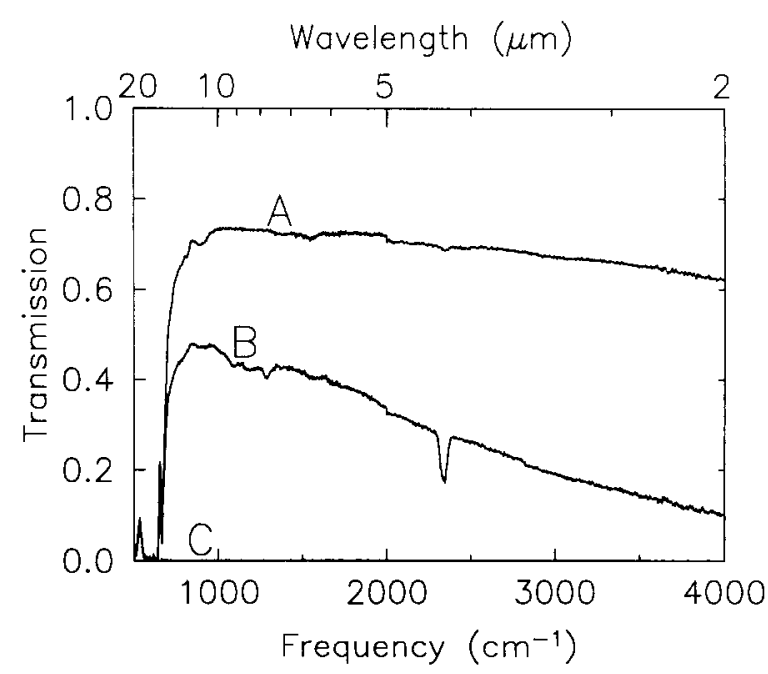

Figure 1 Infrared transmitting spectra of $\mathrm{ZnS}$ with diamond content of (A) 0,(B) $2 \mathrm{wt} \%$, and (c) $10 \mathrm{wt} \%$. The diamond and $\mathrm{ZnS}$ powders were hand mixed during green state processing. 

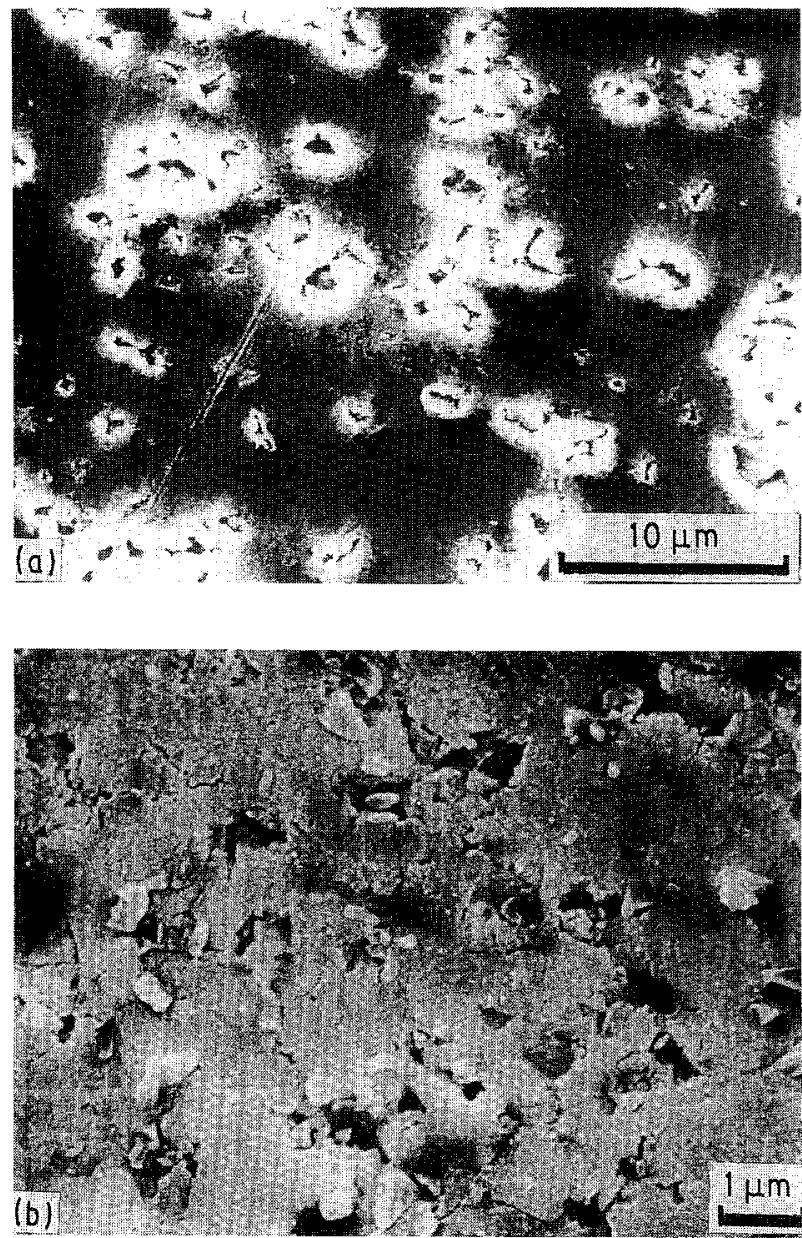

Figure 2 Scanning electron micrographs of (a) a polished section of the $10 \mathrm{wt} \%$ diamond composite (Sample C) in Fig.1, (b) a polished and etched section of Specimen $\mathrm{C}$ in Fig.4 for which the mixing of diamond with $\mathrm{ZnS}$ was accomplished by the combined techniques.

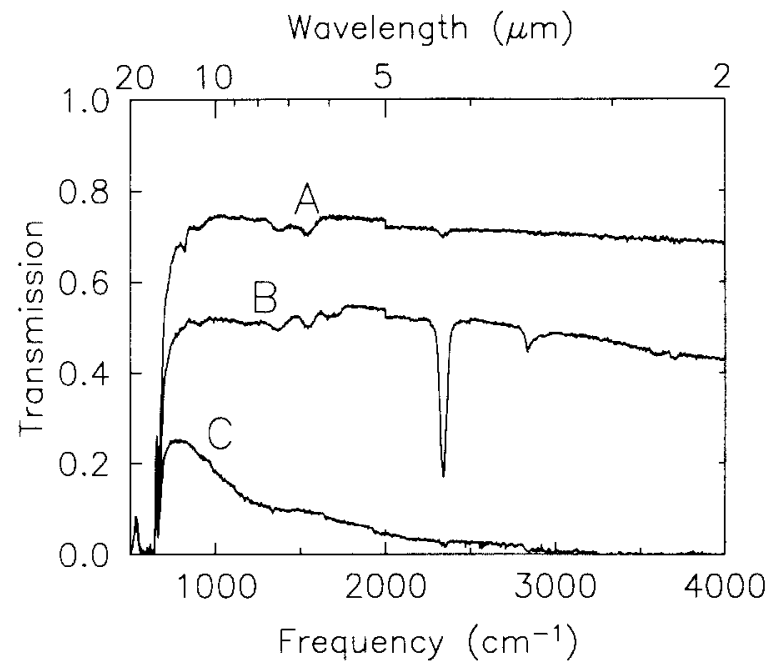

Figure 3 Infrared spectra of $\mathrm{ZnS}$ with diamond content of (A) 0, (B) $2 \mathrm{wt} \%$, and (C) $10 \mathrm{wt} \%$. Ultrasonic treatment was used in the green state processing.

probably be attributed to the hot-pressing atmosphere used for the specimen $\left(\mathrm{Ar}+4 \% \mathrm{H}_{2}\right)$. The optical properties for the $10 \%$ diamond composite were noticably enhanced; the as-measured transmission increased to $20 \%$ at $10 \mu \mathrm{m}$. However, scattering was still the major contributor in the loss, as manifested by the shape of Curve $\mathrm{C}$, and the diamond dispersion needed to be further improved.

Shear stress applied to the diamond-ZnS mixture during shear mixing proved to be effective in eliminating agglomerates and in improving microstructural homogeneity. As shown in Fig. 4, this gave a transmission curve, $B$, superior to that of ultrasonic mixing (Curve A). Impact mixing of the mixture at liquid nitrogen temperature (freeze milling) was also found effective. Microstructural examination of specimens produced by these two techniques indicated the virtual absence of the kind of pits and holes (i.e. diamond agglomerates) seen in Fig. 2a. Moreover, when a combination of these techniques was employed, a further significant increase in transmission was realized (Curve $\mathrm{C}$ ). The corresponding microstructure of this highly transmitting sample can be seen in Fig. $2 b$, which is a scanning electron micrograph of a polished and etched section of that specimen. The diamond particles appear a little darker in the matrix but appear brighter when protruding on the surface. It is evident that a fairly good dispersion of diamond in $\mathrm{ZnS}$ has been achieved.

A further improvement in the optical properties was obtained by refining and optimizing the green state processing conditions of the ultrasonic mixing, shear mixing, and freeze milling. The achievable infrared transmission at $10 \mu \mathrm{m}$ wavelength for $10 \%$ composite has approached that of the pure $\mathrm{ZnS}$. A typical transmission spectrum of a sample produced with the refined procedure is shown in Fig. 5, which is almost completely transparent around the $10 \mu \mathrm{m}$ range (Curve B, compared to Curve $\mathrm{C}$ of pure $\mathrm{ZnS}$ ).

\subsection{Fracture toughness}

The variation of measured toughness, $\mathrm{K}_{\mathrm{Ic}}$, as a function of increasing weight fraction of diamond particles for the composite is shown in Fig. 6. The data are

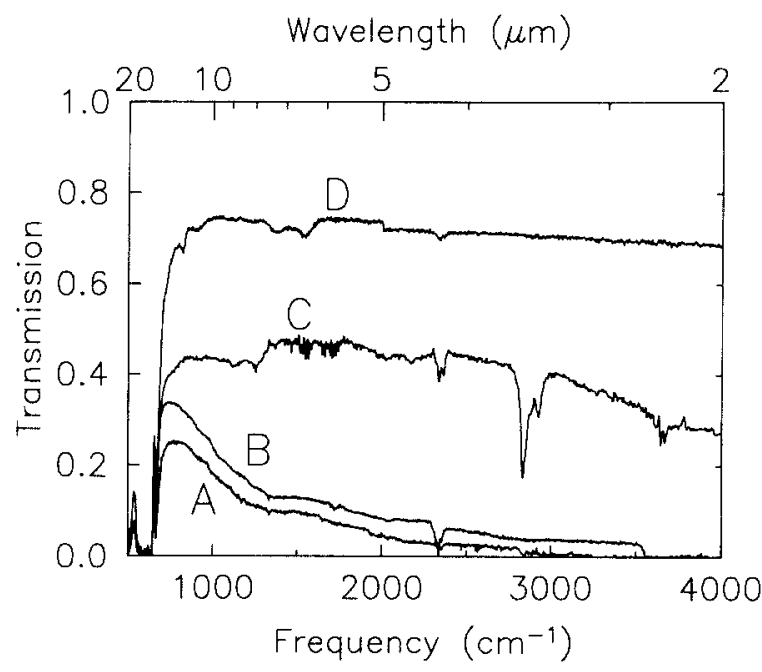

Figure 4 Infrared spectra of pure ZnS (Curve D) and $10 \mathrm{wt} \%$ diamond composites which underwent different green state mixing procedures (A) ultrasonic mixing, (B) shear mixing, and (C) a combination of ultrasonic, shear mixing and freeze milling. 


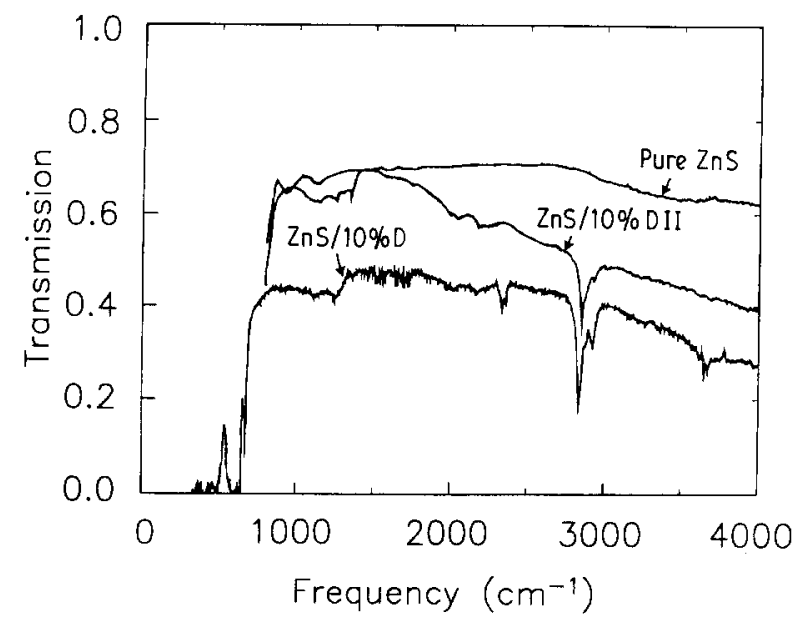

Figure 5 Infrared spectra of pure $\mathrm{ZnS}$ and $10 \mathrm{wt} \%$ diamond composites where comparison can be made between pure $\mathrm{ZnS}$ and $10 \mathrm{wt} \%$ diamond composite $(\mathrm{ZnS} / 10 \% \mathrm{DII})$ from refined processing procedure. Zns $/ 10 \% \mathrm{D}$ is the same as Sample C seen in Fig.4.

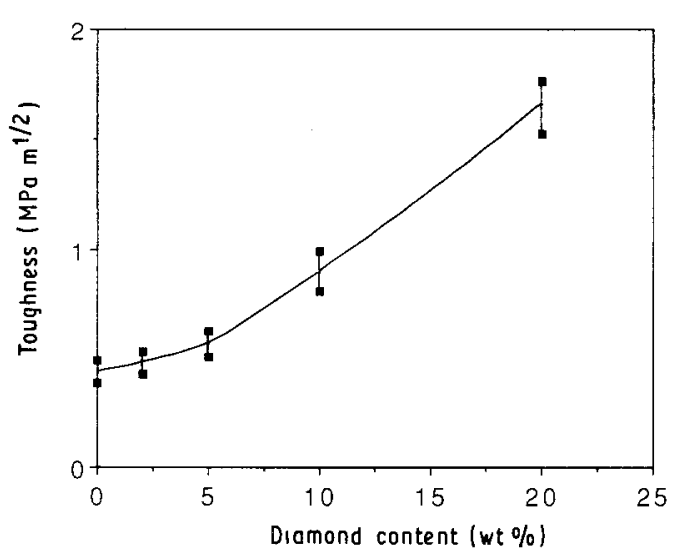

Figure 6 Toughness, $\mathrm{K}_{\mathrm{Ic}}$, as function of diamond content for diamond-ZnS composites. The data were obtained using Vickers indentor at load of $6 \mathrm{~N}$.

calculated using the equation given by Lawn and Fuller [7]

$$
K_{\mathrm{Ic}}=P(\pi c)^{-3 / 2} / \operatorname{tg} \phi
$$

where $P$ is the indentation load, $c$ the crack length, and $\phi$ is half of the apex angle $\left(136^{\circ}\right)$ of the Vickers indentor. Our experimental crack length data as a function of the applied indentation load shows a power-law dependence of 1.5 , which justifies the use of Equation 2 in the computation of the indentation results in the present study.

Fig. 6 shows a clear trend toward increasing toughness with increasing diamond content. Toughness measurements performed on specimens made by various mixing techniques yielded similar $K_{\mathrm{Ic}}$ values (the differences were within the error bars in Fig. 6), indicating the relative independence of the microtoughness on the quality of diamond dispersion, compared to that of optical transmission. This is not surprising, because the crack lengths of the Vicker indents were about two orders of magnitude larger than the sizes of diamond agglomerates seen in Fig. 2a, whereas the

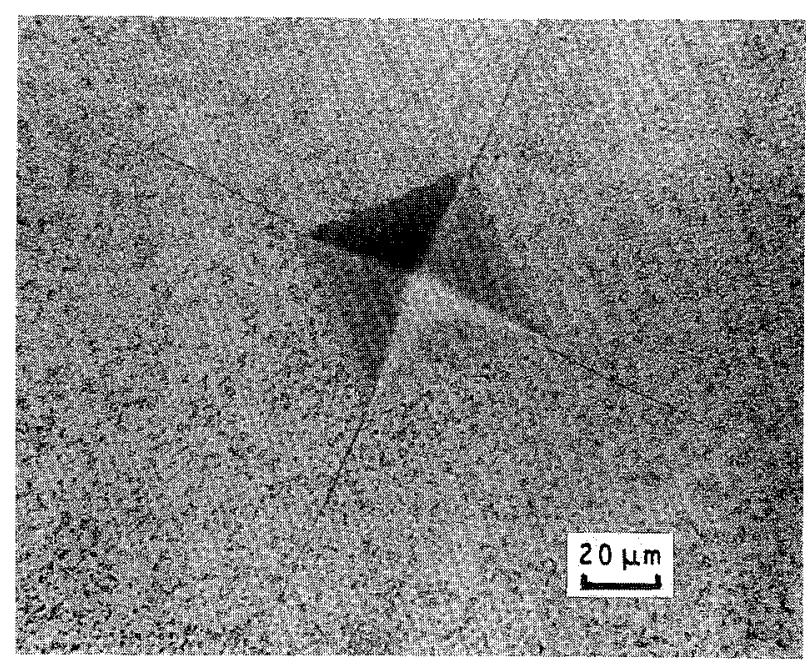

Figure 7 Optical micrograph of a typical indent in a $10 \mathrm{wt} \%$ diamond composite.

wavelengths of the incident lights were comparable to the latter. On the other hand, it is rather striking that the addition of only $10 \mathrm{wt} \%$ diamond raises the $K_{\text {Ic }}$ of $\mathrm{ZnS}$ by a factor of two, and $20 \mathrm{wt} \%$ diamond more than triples the value. Fig. 7 illustrates a typical hardness indent seen under an optical microscope in $10 \%$ diamond composite. The toughness value obtained for pure $\mathrm{ZnS}\left(0.44 \mathrm{MPa} \mathrm{m}^{1 / 2}\right)$ is in surprisingly good agreement with the reported value of $0.44 \pm$ 0.08 measured by the single-edge-notched beam method for hot-pressed $\mathrm{ZnS}$ [9].

\section{Conclusions}

The infrared transparency of diamond particulate $\mathrm{ZnS}$ ceramic composite depends strongly on the quality of diamond dispersion upon which the green state processing has a profound influence. Scattering is the main cause of loss in transmission. The microtoughness of the composite is relatively independent of green state processing conditions, increasing with the addition of diamond particles. $10 \mathrm{wt} \%$ diamond composite exhibits a degree of transmission approaching that of pure $\mathrm{ZnS}$ in the far infrared range, and also shows a more than $100 \%$ increase in toughness as compared to single-phase $\mathrm{ZnS}$.

\section{Acknowledgements}

The authors thank Dr T.W. Noh and Professor A.J. Sievers for their help in the optical transmission measurement. This research was supported by the Office of Naval Research. Support was also received from the National Science Foundation through the use of the facilities of the materials Science Center at Cornell.

\section{References}

1. I. W. DONALD, P. W. McMillan, J. Mater. Sci. 13 (1978) 1151. 
2. C. D. CLARK, R. W. DICHBURN and H. B. DYER, Proc. $R$. Soc. Lond. A234 (1956) 363.

3. L. A. XUE, D. S. FARQUHAR, T. W. NOH, A. J. SIEVERS and R. RAJ, Acta Metall, 38 (1990) 1743,

4. F. F. LANGE, J. Amer Ceram. Soc. 54 (1971) 614.

5. W. B. Hilling, Ann. Rev. Mater. Sci. 17 (1987) 341.

6. C. F. BOHREN and D. R. HUFFMAN, "Absorption and Scattering of Light by Small Particles" (Wiley, New York, 1983).
7. B. R. LAWN and E. R. FULLER, J. Mater. Sci. 10 (1975) 2016

8. A. G. EVANS and E. A. CHARLES, J. Amer, Ceram. Soc. 59 (1976) 371 .

9. H. P. KIRCHNER, J. A. TIRACORDA and T. J. LARCHUK, ibid. 67 (1984) C188.

Received 6 February

and accepted 14 June 1991 